Article

\title{
Flow Behavior and Hot Processing Map of GH4698 for Isothermal Compression Process
}

\author{
Rongchuang Chen ${ }^{1, *} \mathbb{D}$, Haifeng Xiao ${ }^{1}$, Min Wang ${ }^{1, *}$ and Jianjun $\mathrm{Li}^{2}$ \\ 1 School of Materials Science and Engineering, Hubei University of Automotive Technology, \\ Shiyan 442002, China \\ 2 School of Materials Science and Engineering, Huazhong University of Science and Technology, and State Key \\ Laboratory of Materials Processing and Die \& Mould Technology, Wuhan 430074, China \\ * $\quad$ Correspondence: crc@hust.edu.cn (R.C.); minwang@126.com (M.W.); Tel.: +86-134-7628-4413 (R.C.); \\ +86-134-7730-6746 (M.W.)
}

Received: 1 July 2019; Accepted: 29 July 2019; Published: 1 August 2019

check for updates

\begin{abstract}
An in-depth understanding of the flow behaviors of materials deformed at high temperatures is of paramount significance. However, insufficient research on the nickel-based GH4698 alloy has resulted in inaccurate material flow prediction or even cracking in the practical billet opening of GH4698 large forgings. In this study, hot compressions were performed at $950-1150{ }^{\circ} \mathrm{C}$ and $0.001-3 \mathrm{~s}^{-1}$. Single-peaked strain-stress curves were obtained under various conditions, owing to dislocation motions in dynamic recrystallizations. The Arrhenius model was formulated to accurately describe the flow stress evolutions and the mean prediction error of the flow stress was $5.90 \%$. Processing maps were constructed at various hot working conditions. It was found that the hot working ability of GH4698 markedly decreased under lower temperatures (950-1080 ${ }^{\circ} \mathrm{C}$ ) and higher strain rates $\left(0.1-3 \mathrm{~s}^{-1}\right)$. Optimal thermal processing parameters were suggested. In sum, this study systematically investigated the flow behaviors and hot working ability of GH4698 in isothermal compressions.
\end{abstract}

Keywords: processing maps; nickel-based alloy; flow behavior; arrhenius equation

\section{Introduction}

As a type of precipitation-reinforced nickel-based high-temperature alloy, the GH4698 alloy has excellent strength, toughness, fatigue resistance, and corrosion resistance at up to $750{ }^{\circ} \mathrm{C}$. Thus, this alloy has been widely used to manufacture machine parts working at high temperatures, such as airplane engine compressor disks, guide vanes, and gas turbine disks. However, this material is extremely sensitive to thermal processing parameters, and cracking could easily occur in the billet opening of GH4698 large forgings, owing to the addition of aluminum and titanium [1]. One solution could be to place the billet in a sleeve and forge as a whole, so that the material is under a three-dimensional compressive stress state, but this would increase the cost. A more economical method is to deform under optimized parameters, but thus far, hot processing maps of GH4698 have not been established, hindering the hot working parameters optimization in practical production. Therefore, there is an urgent need for systematic research on the flow behaviors and hot working maps of GH4698.

Various flow stress models have been proposed to describe the flow behaviors of alloys at high temperatures. The phenomenological Johnson-Cook model was successfully used to describe the exponential stress-strain relationships of GH4133B by Wang et al. [2]. However, the Johnson-Cook model was inadequate for materials with nonexponential type stress-strain curves, and the Zerilli-Armstrong model was established for an NiTi alloy by Shamsolhodaei et al. [3]. To achieve a higher prediction accuracy, the Arrhenius model was modified to incorporate the influence of strain, and based on the modified Arrhenius model, flow stress models were established for various nickel-based alloys, e.g., 
the GH4169 alloy by Chen et al. [4], N08028 alloy by Wang et al. [5], and 80A alloy by Gu et al. [6]. The results by Lin et al. [7] and Wang et al. [8] indicated that the accuracy of the flow stress models could be further improved by a neural network, but the applications were limited, owing to the difficulty in finite elemental integration. Moreover, physical-based models were proposed to investigate the underlying mechanisms of the influences of creep, dislocation motion, and grain size on flow stresses by Lin et al. [9], Haan et al. [10], and Zhou et al. [11]. By comparing the above-mentioned models, the Arrhenius model showed an advantage in applicability and accuracy, and thus it has been widely used in the flow stress modeling of nickel-based alloys [4-6].

The processing maps of nickel-based alloys have also been investigated intensively in recent years. Hot working maps of a nickel-based alloy for power plant applications were established by Wu et al., and it was revealed that the different recrystallization mechanisms could be reflected by the hot working maps [12]. The microstructures on the different domains of the processing maps of the IN028 alloy were inspected by Wang et al. [13], and the study showed that the deformation mechanism maps agreed well with the processing maps. The processing maps of the N08028 alloy [14], the 617B alloy [15], and the GH4169 alloy [16] showed that the efficiency peaks of the processing maps were associated with dynamic recrystallization nucleation and dramatic grain growth of the N08028 alloy, whereas incomplete recrystallization, twinning, and adiabatic shear bands occurred in the instability domain. By comparing the different instability criterions from Gegel et al. [17-20], the different shapes of the deformation instability domains of GH79 alloy were compared by Ge et al. [21], and it was noted that the deformation instability domains from Prasad's criterion could effectively predict the deformation instability of GH79. It was shown by the result of Chen et al. [4] that the optimal hot working parameters of GH4169 were located at areas whose dissipative efficiencies were 30-35\%. Specifically, for the GH4698 alloy, the flow behaviors were investigated by Zhang et al. [22], and a flow stress model was established. Nevertheless, hot working maps of GH4698 have not been established, forming a barrier for hot working parameter optimization in large forging production. Thus, systematic research is required on the flow behaviors and hot workability of the GH4698 alloy at high temperatures.

Therefore, in this study, the hot deformation behaviors of the GH4698 alloy were studied via hot compressions. An Arrhenius model was established to calculate the flow stresses. Processing maps at various thermal processing conditions were constructed, and an optimal hot working parameter range for GH4698 was recommended. This study provides a reference for hot working parameter optimization of GH4698 large forgings during the forging process.

\section{Materials and Experiments}

\subsection{Materials}

The as-forged GH4698 alloy ingot used in this study had a size of $\Phi 300 \mathrm{~mm} \times 1000 \mathrm{~mm}$. The chemical composition of the GH4698 alloy was quantified via x-ray fluorescence (XRF1800, Shimadzu Inc., Kyoto, Japan) and an infrared carbon-sulfur analyzer (CS2800, Eltra Inc., Haan, Germany), as shown in Table $1[23,24]$. It should be noted that the carbon content of the material used in this research was at the upper limit allowed for GH4698. The specimens for elemental analysis were prepared by wire electrode cutting, turning, and mechanical polishing to $\Phi 33 \mathrm{~mm} \times 12 \mathrm{~mm}$ cylinders. The hot compression specimens were prepared by wire electrode cutting and turning to $\Phi 8 \mathrm{~mm} \times 12 \mathrm{~mm}$ cylinders.

Table 1. Composition of the GH4698 alloy.

\begin{tabular}{cccccccccc}
\hline Composition & $\mathbf{C}$ & $\mathbf{A l}$ & $\mathbf{F e}$ & $\mathbf{C r}$ & $\mathbf{N b}$ & $\mathbf{Z r}$ & $\mathbf{M o}$ & $\mathbf{T i}$ & $\mathbf{N i}$ \\
\hline Mass Percentage $(\%)$ & 0.08 & 1.55 & 1.51 & 14.43 & 1.95 & 0.05 & 2.90 & 2.62 & Balance \\
\hline
\end{tabular}




\subsection{Experiments}

Hot compressions were conducted on a compression machine (Gleeble3500, Dynamic Systems Inc., Austin, TX, USA). The compression temperatures were determined to be $950{ }^{\circ} \mathrm{C}, 1000^{\circ} \mathrm{C}, 1050{ }^{\circ} \mathrm{C}$, $1100{ }^{\circ} \mathrm{C}$, and $1150^{\circ} \mathrm{C}$, respectively. These temperatures covered the usual hot working temperature range of GH4698 [1]. To cover the strain rate range of the billet forging process, preforging process, and final-forging process of large forgings on hydraulics, the strain rates were selected to be $0.001 \mathrm{~s}^{-1}$, $0.01 \mathrm{~s}^{-1}, 0.1 \mathrm{~s}^{-1}, 1 \mathrm{~s}^{-1}$, and $3 \mathrm{~s}^{-1}$, respectively. The experimental procedure is shown in Figure 1 . The specimens were heated to $1150{ }^{\circ} \mathrm{C}$ at $3.3^{\circ} \mathrm{C} / \mathrm{s}$, held for $180 \mathrm{~s}$, cooled to deformation temperatures, held for $180 \mathrm{~s}$, compressed to the strain of 0.95 , and quenched. The true stress and logarithmic strain were calculated accordingly. The compressive strains, which had negative values, were written as positive for simplicity in this research. Smoothing was applied on the stress-strain curves.

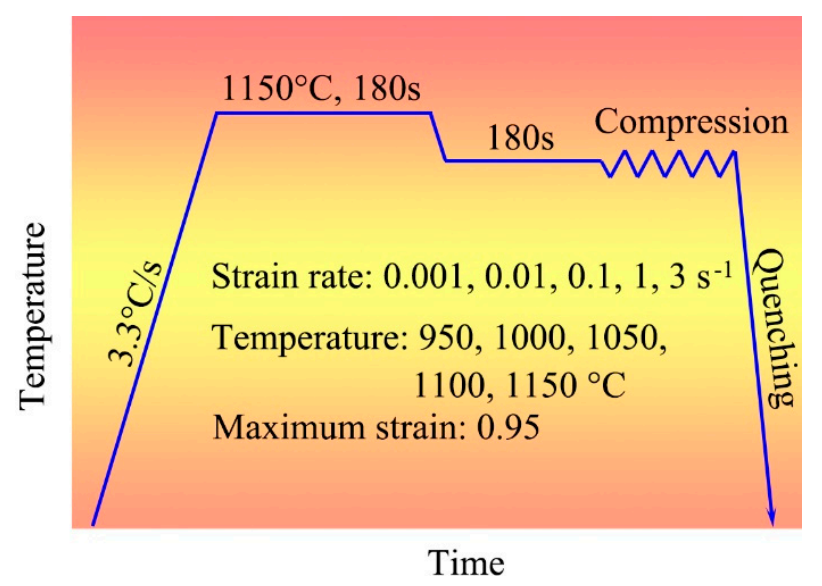

Figure 1. Illustration of the experiment procedure.

\section{Results and Discussion}

\subsection{Flow Behaviors}

The stress-strain curves of GH4698 at various strain rates are shown in Figure 2. Basically, single-peak flow stress curves were obtained. In the starting stage of deformation, the flow stress increased because of the contradicting effect of work hardening by dislocation pile ups and cross slips, as well as dynamic softening, by creep and recovery. As the deformation proceeded, the dislocation densities at the grain boundaries reached the critical value for recrystallization, and the dynamic recrystallized grains nucleated, resulting in the softening and a gradual drop in the flow stress [25]. When the dynamic recrystallization was completed, the flow stress remained nearly constant, as the hardening effect and the softening effect were balanced. It can also be seen from Figure 2 that the flow stress decreased with increasing temperature. This could be explained by the observation that the thermal movement of atoms was more intense at higher temperatures. The creep and dynamic recrystallization were more likely to occur owing to fewer obstacles for the dislocation motion to overcome, resulting in the overall softening of the GH4698 alloy. With the increasing strain rate, the flow stress increased. This is because at a faster strain rate, it was more difficult for the dynamic recovery to fully occur, leading to a higher average dislocation density and a greater deformation resistance. It is worth noting that the peak flow stress shown in Figure 2 agreed well with the results of Zhang et al. [22], but the curve shapes were different, which may be attributed to differences in the composition of as-received material. As mentioned in Section 2.1, the carbon content of the material used in this research, $0.08 \%$, was obviously higher than that in the literature [22], $0.048 \%$. For nickel-based alloys, Chen et al. [4] and Lin et al. [7] proved that dynamic recrystallization occurred during hot compressions. Therefore, a refined and uniform microstructure could be obtained by 
selecting optimal hot working parameters. In this way, the hot working ability could be improved, and cracking defects of large forgings in the billet opening process could be avoided.

(a)

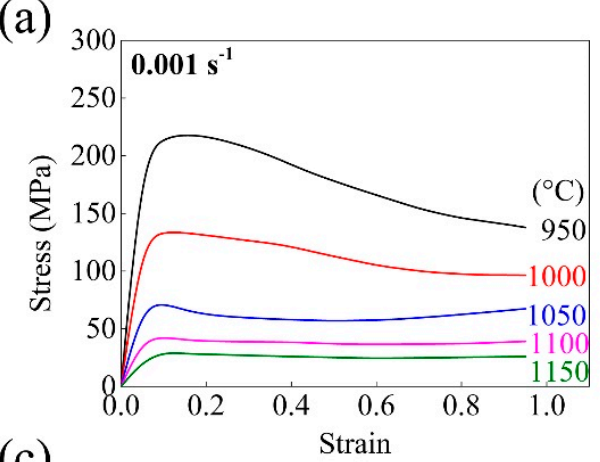

(c)

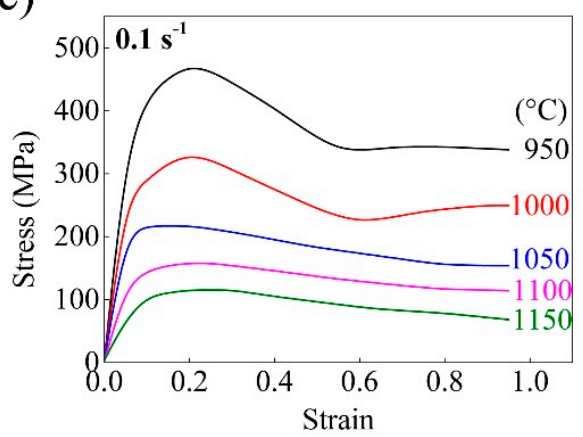

(b)

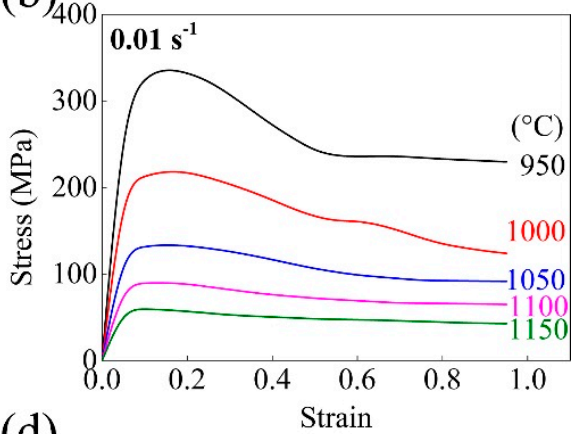

(d)

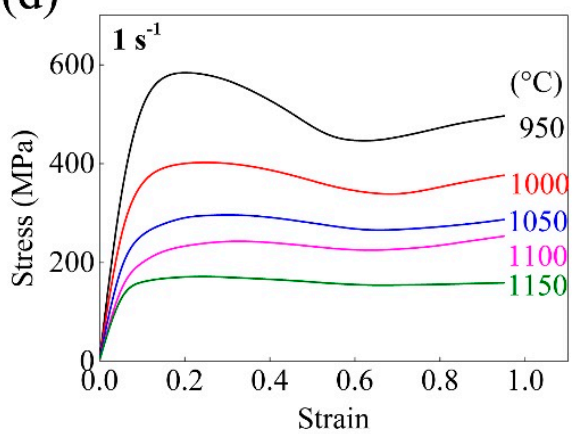

(e)

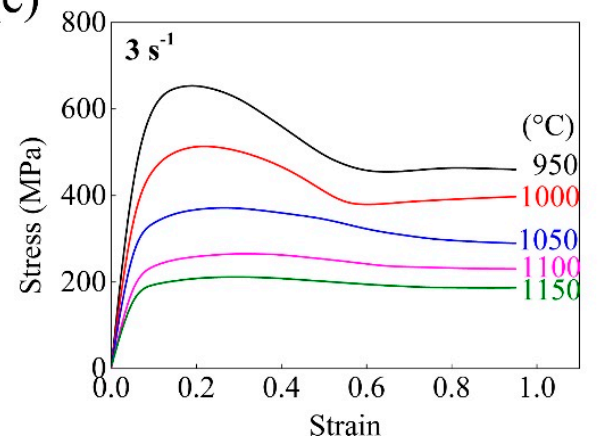

Figure 2. Stress strain curves of GH4698 compressed at the strain rates of (a) $0.001 \mathrm{~s}^{-1}$, (b) $0.01 \mathrm{~s}^{-1}$, (c) $0.1 \mathrm{~s}^{-1},(\mathbf{d}) 1 \mathrm{~s}^{-1}$, and (e) $3 \mathrm{~s}^{-1}$.

\subsection{Flow Stress Modeling}

Although a flow stress model of the GH4698 alloy was established by Zhang et al. [22], different shapes of stress-strain curves were obtained under various compression conditions, as shown in Figure 2. Therefore, a flow stress model describing the stress-strain relationships of GH4698 should be established. The Arrhenius equation was expressed as in [26]:

$$
\dot{\varepsilon} \exp \left(\frac{Q}{R T}\right)=A(\sinh (\alpha \sigma))^{n} .
$$

Here, $A, n$, and $\alpha$ were material constants, was the strain rate in $\mathrm{s}^{-1}, Q$ was the thermal activation energy in $\mathrm{kJ} /(\mathrm{mol} \cdot \mathrm{K}), R$ was the gas constant, which equaled $8.314 \mathrm{~J} /(\mathrm{mol} \cdot \mathrm{K})$, and $T$ was the deformation temperature in K. As a constraint, the following could be applied for different stress levels [27,28]:

$$
\dot{\varepsilon}=A_{1} \sigma^{n} \exp \left(-\frac{Q}{R T}\right) \quad(\alpha \sigma<0.8)
$$




$$
\dot{\varepsilon}=A_{2} \exp (\beta \sigma) \exp \left(-\frac{Q}{R T}\right) \quad(\alpha \sigma>1.2) .
$$

$A_{1}, A_{2}, n$, and $\beta$ are constants, which follows:

$$
\alpha=\frac{\beta}{n}
$$

Taking logarithms of both sides of Equations (2) and (3) gives:

$$
\begin{gathered}
\ln \dot{\varepsilon}=\ln A_{1}+n \ln \sigma-\frac{Q}{R T} \\
\ln \dot{\varepsilon}=\ln A_{2}+\beta \sigma-\frac{Q}{R T} .
\end{gathered}
$$

Thus, $n$ and $\beta$ could be calculated by the slopes of the fitted line of $\ln \sigma$ versus $\ln \dot{\varepsilon}$, and $\sigma$ versus $\ln \dot{\varepsilon}$. The value of $\alpha$ is calculated according to Equation (4). Taking a logarithm of Equation (1) results in:

$$
\ln \dot{\varepsilon}=\ln A+n \ln (\sinh (\alpha \sigma))-\frac{Q}{R T} .
$$

Therefore, the value of $Q$ could be obtained via the slope of the fitted line of $\frac{1}{T}$ versus $\ln (\sinh (\alpha \sigma))$, and the value of $\ln A$ could be obtained via the intercept of the fitted line of $\ln (\sinh (\alpha \sigma))$ versus $\ln \dot{\varepsilon}+\mathrm{Q} / R T$. Taking $\varepsilon=0.05$ as example, the calculation process of the model parameters is shown in Figure 3. For effectiveness, the calculations were made using MATLAB software at various strains. The values of the model parameters with the increasing strain are shown in Figure 4.
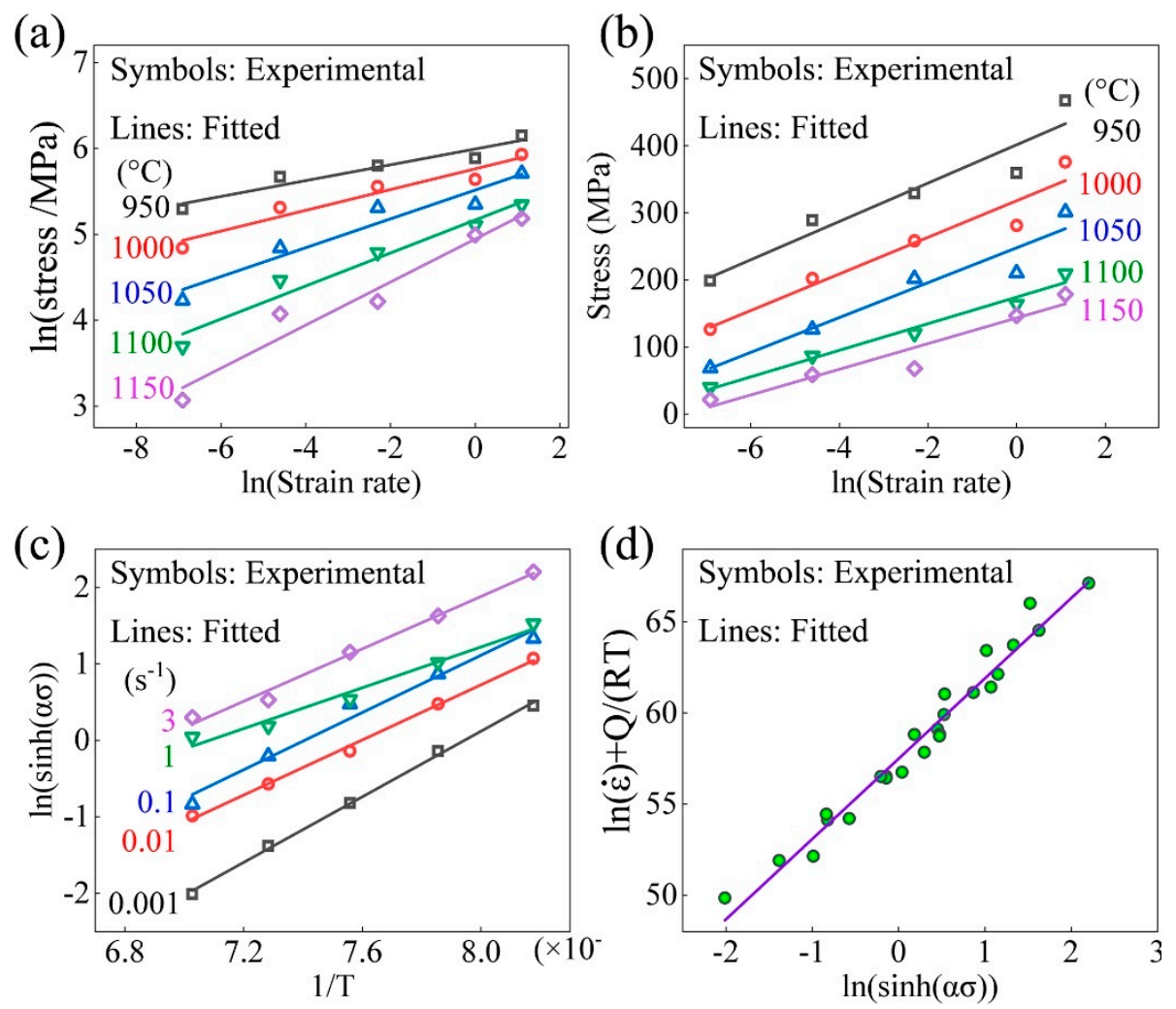

Figure 3. The calculation process of $n, \beta, Q$, and $\ln A$ from the slope of the fitted line of (a) $\ln \sigma$ versus $\ln \dot{\varepsilon}$, (b) $\sigma$ versus $\ln \dot{\varepsilon}$, (c) $\frac{1}{T}$ versus $\ln (\sinh (\alpha \sigma))$, and from the intercept of the fitted line of $(\mathbf{d}) \ln (\sinh (\alpha \sigma))$ versus $\ln \dot{\varepsilon}+\frac{\mathrm{Q}}{R T}$. 

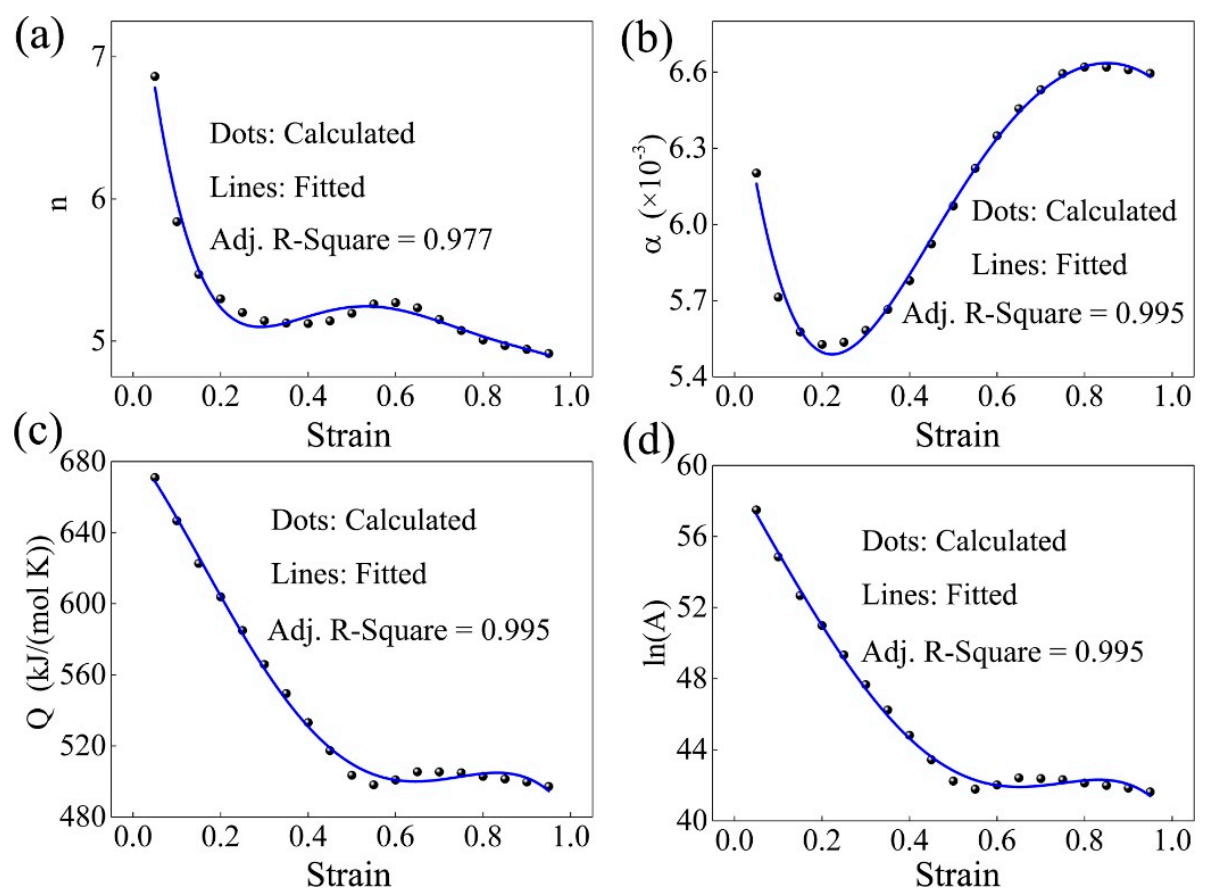

Figure 4. The Arrhenius model parameter values of GH4698 alloy at various strains. (a) $n$, (b) $\beta$, (c) $Q$, and (d) $\ln A$.

Fifth-order polynomial fittings were then applied to describe the relationships between the model parameters and the strain, resulting in the following:

$$
G=k_{0}+k_{1} \varepsilon+k \varepsilon^{2}+k_{3} \varepsilon^{3}+k_{4} \varepsilon^{4}+k_{5} \varepsilon^{5} .
$$

Here, $G$ denotes $n, \beta, Q$, and $\ln A$, respectively. $k_{0}-k_{5}$ denote the coefficients, whose values are determined by polynomial fitting in the Origin software, shown in Table 2.

Table 2. Coefficients of the polynomials.

\begin{tabular}{ccccccc}
\hline Coefficients & $k_{\mathbf{0}}$ & $\boldsymbol{k}_{\mathbf{1}}$ & $\boldsymbol{k}_{\mathbf{2}}$ & $\boldsymbol{k}_{\mathbf{3}}$ & $\boldsymbol{k}_{\mathbf{4}}$ & $\boldsymbol{k}_{\mathbf{5}}$ \\
\hline$n$ & $7.993 \times 10^{0}$ & $-2.922 \times 10^{1}$ & $1.083 \times 10^{2}$ & $-1.825 \times 10^{2}$ & $1.426 \times 10^{2}$ & $-4.233 \times 10^{1}$ \\
$\alpha$ & $6.731 \times 10^{-3}$ & $-1.372 \times 10^{-2}$ & $5.024 \times 10^{-2}$ & $-7.115 \times 10^{-2}$ & $4.724 \times 10^{-2}$ & $-1.283 \times 10^{-2}$ \\
$Q$ & $6.870 \times 10^{5}$ & $-3.307 \times 10^{5}$ & $-7.459 \times 10^{5}$ & $1.830 \times 10^{6}$ & $-7.715 \times 10^{5}$ & $-1.887 \times 10^{5}$ \\
$\ln A$ & $5.492 \times 10^{1}$ & $-4.353 \times 10^{1}$ & $-1.359 \times 10^{0}$ & $3.554 \times 10^{1}$ & $4.416 \times 10^{1}$ & $-5.413 \times 10^{1}$ \\
\hline
\end{tabular}

The comparisons between the calculated and experimental flow stress values are shown in Figure 5. Basically, the flow stress could be predicted with good accuracy, showing that the Arrhenius model was capable of accurately calculating the flow behaviors of GH4698 under various strain rates. The scatter plots of the calculated versus experimental flow stress are shown in Figure 6. The calculated stresses fit well with the experimental stresses. The adjusted $\mathrm{R}$ square value to describe the goodness of fit was 0.990 . The average calculation error was $10.96 \mathrm{MPa}(5.90 \%)$. The errors may be attributed to the following two reasons. First, there were still computational deviations in the fitting of model parameters by the fifth-order polynomial, which could be improved by trying better fitting expressions. Additionally, an abnormal softening occurred in the final part of the stress-strain curve under $1000^{\circ} \mathrm{C}$ and $0.01 \mathrm{~s}^{-1}$, which may be caused by experimental deviations. The number of repetitions under the same hot compression conditions could be increased to reduce such deviations. 
(a)

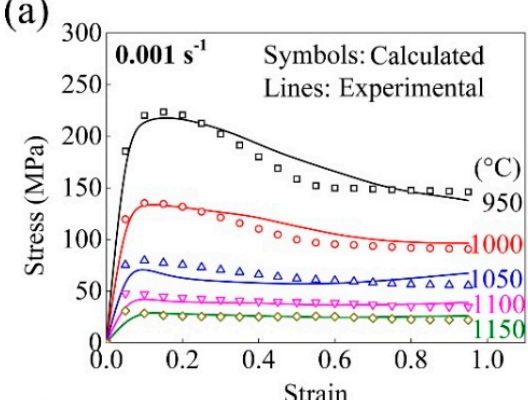

(c)

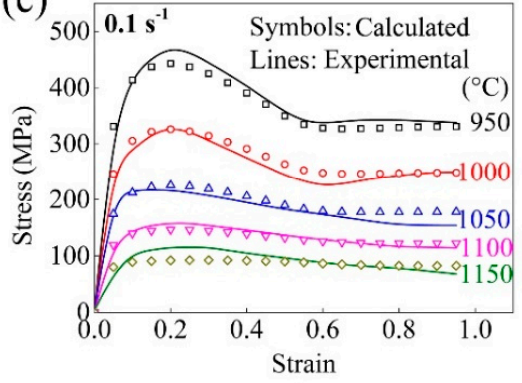

(b)

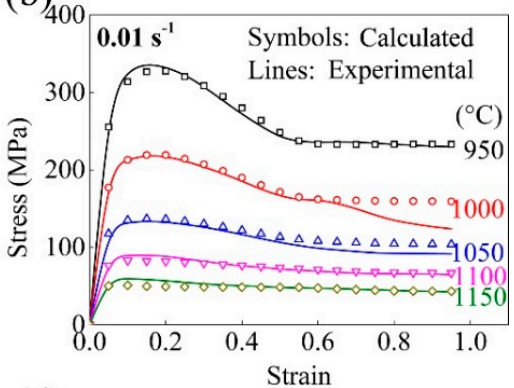

(d)

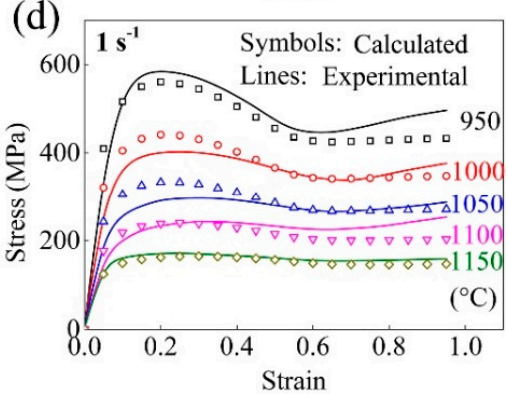

(e) $8 0 0 \longdiv { 3 \mathrm { s } ^ { - 1 } } \quad$ Symbols: Calculated

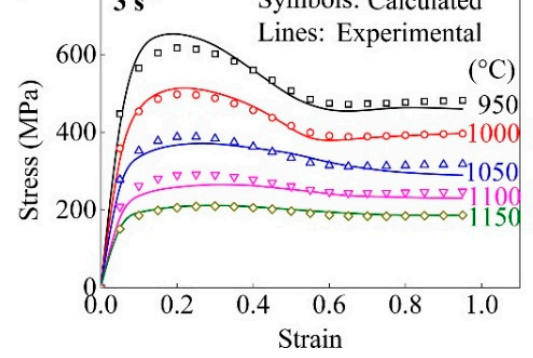

Figure 5. Comparisons of the calculated and experimental flow stress at the strain rates of (a) $0.001 \mathrm{~s}^{-1}$, (b) $0.01 \mathrm{~s}^{-1}$, (c) $0.1 \mathrm{~s}^{-1}$, (d) $1 \mathrm{~s}^{-1}$, and (e) $3 \mathrm{~s}^{-1}$.

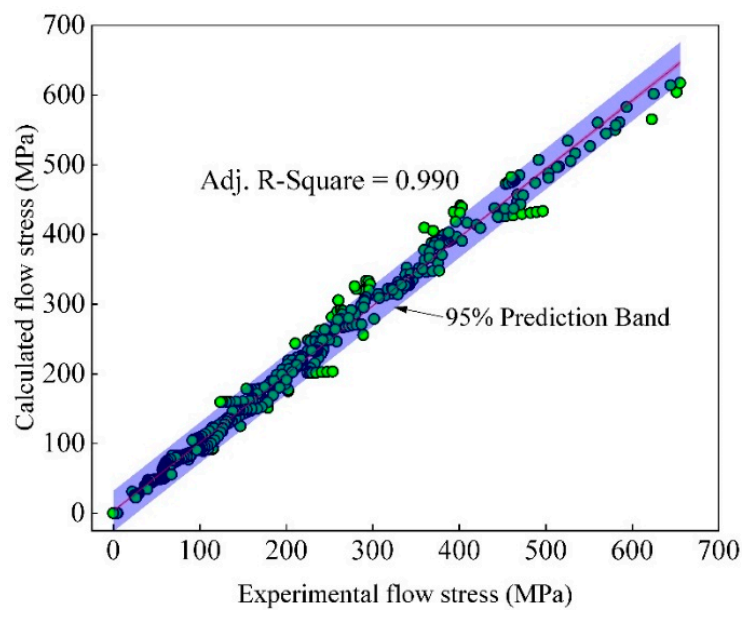

Figure 6. Scatter plots of the calculated versus experimental flow stress.

\subsection{Processing Maps}

The processing maps were significant references for process parameter optimizations of GH4698 large forgings. It was suggested by Prasad et al. [26] that the deformation work $(P)$ during forging is consumed by temperature rising $(G)$ and microstructure evolution $(J)$, as represented by: 


$$
P=G+J=\int_{0}^{\dot{\varepsilon}} \sigma \mathrm{d} \dot{\varepsilon}+\int_{0}^{\sigma} \dot{\varepsilon} \mathrm{d} \sigma .
$$

The power dissipation coefficient $(\eta)$ quantifying the fraction of energy by microstructure evolution was calculated by [4]:

$$
\eta=\frac{2 \frac{\partial \ln \sigma}{\partial \ln \dot{\varepsilon}}}{\frac{\partial \ln \sigma}{\partial \ln \dot{\varepsilon}}+1} .
$$

An instability coefficient $\zeta$ for predicting deformation instability was expressed as in [4]:

$$
\zeta=\frac{\partial \log (\eta / 2)}{\partial \log (\dot{\varepsilon})}+\frac{\partial \ln \sigma}{\partial \ln \dot{\varepsilon}} .
$$

The value of $\zeta$ was negative when deformation instability occurred according to previous research [4,12-15]. The value of $\sigma$ could be obtained from the flow stress model. Thus, the thermal processing maps of GH4698 were established according to Equations (10) and (11), as shown in Figure 7. The deformation instability was shown as shaded areas, and the dissipation coefficients were shown as contours. At a strain of 0.2 (Figure 7a), three deformation instability domains were found. One was located at $950-1150{ }^{\circ} \mathrm{C}$ and $0.25-3 \mathrm{~s}^{-1}$, another at $985-1015{ }^{\circ} \mathrm{C}$ and $0.001-0.002 \mathrm{~s}^{-1}$, and the third at $1060-1140{ }^{\circ} \mathrm{C}$ and $0.001-0.004 \mathrm{~s}^{-1}$. As the strain increased to 0.4 , the deformation instability domain at high strain rates split into two, one at $950-1025^{\circ} \mathrm{C}$ and $0.5-3 \mathrm{~s}^{-1}$, and the other at $1060-1150{ }^{\circ} \mathrm{C}$ and $0.5-3 \mathrm{~s}^{-1}$. Another deformation instability domain was located at $960-1010^{\circ} \mathrm{C}$ and $0.002-0.025 \mathrm{~s}^{-1}$. A comparison of data presented in Figure $7 \mathrm{a}, \mathrm{b}$ showed that the majority of the deformation instability domain had dissipation coefficients lower than $35 \%$, and the dissipation coefficients of the other parts of the map were generally greater than $35 \%$. One reason for this could be that at higher strain rates and lower temperatures, dynamic recrystallization was insufficient, and deformation instability occurred more easily. Thus, a much larger proportion of the deformation work was converted into heat. At a strain of 0.6 (Figure 7c), two deformation instability domains were found. One was located at $950-975{ }^{\circ} \mathrm{C}$ and $0.3-3 \mathrm{~s}^{-1}$, and the other at $1070-1140{ }^{\circ} \mathrm{C}$ and $0.5-3 \mathrm{~s}^{-1}$. It is worth noting that the dissipation coefficients were high in the lower right part of the map in Figure $7 c$, which corresponds to high temperature and low strain rate conditions, and this may be because of the dramatic grain growth after the dynamic recrystallization was completed. At a strain of 0.8 (Figure $7 \mathrm{~d}$ ), two deformation instability domains occurred. One existed at $950-1070{ }^{\circ} \mathrm{C}$ and $0.05-0.63 \mathrm{~s}^{-1}$, and the other at $1080-1150{ }^{\circ} \mathrm{C}$ and $0.4-3 \mathrm{~s}^{-1}$. The overlapping of the processing maps in Figure $7 \mathrm{a}-\mathrm{d}$ reveals that to avoid deformation instability, the hot working parameters should drop in the area of $1080-1150{ }^{\circ} \mathrm{C}$ and $0.004-0.05 \mathrm{~s}^{-1}$.

The processing maps at various temperatures or strain rates are extremely important for the hot working parameter optimization when the deformation temperature or the punch speed are restrained. The processing maps of the GH4698 alloy at various temperatures could be obtained by slicing and interpolating the processing maps at specific temperatures, as shown in Figure 8. A deformation instability domain at a strain of $0.2-0.8$ and at a strain rate of $0.1-3 \mathrm{~s}^{-1}$ was found under $950{ }^{\circ} \mathrm{C}$ (Figure 8a). The dissipation coefficients were below 25\%. A comparison with data provided in Figure 8a indicated that much smaller deformation instability domains existed under $1050{ }^{\circ} \mathrm{C}$, as shown in Figure 8 b. At $1150^{\circ} \mathrm{C}$ (Figure $8 \mathrm{c}$ ), the deformation instability domain disappeared. Figure 8 shows that the workability of the GH4698 alloy was improved by dynamic recrystallization under higher hot working temperatures. It is worth noting that the dissipation coefficients generally increased with increasing temperature, because the dynamic recrystallization was more complete at higher temperatures, thereby consuming a much larger proportion of energy. 
(a)

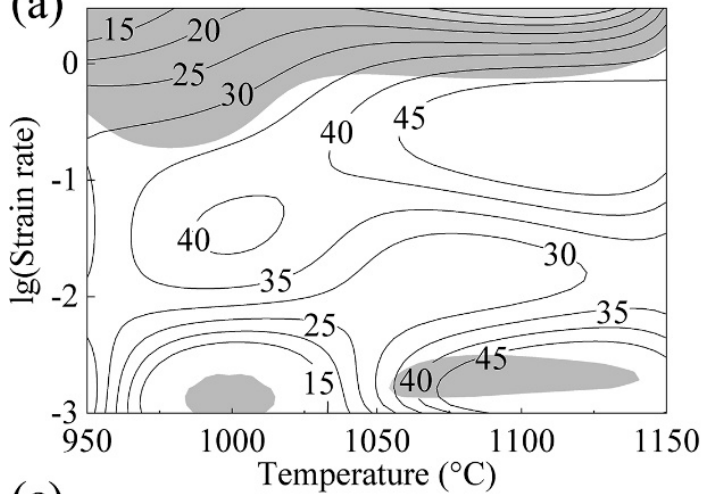

(c)

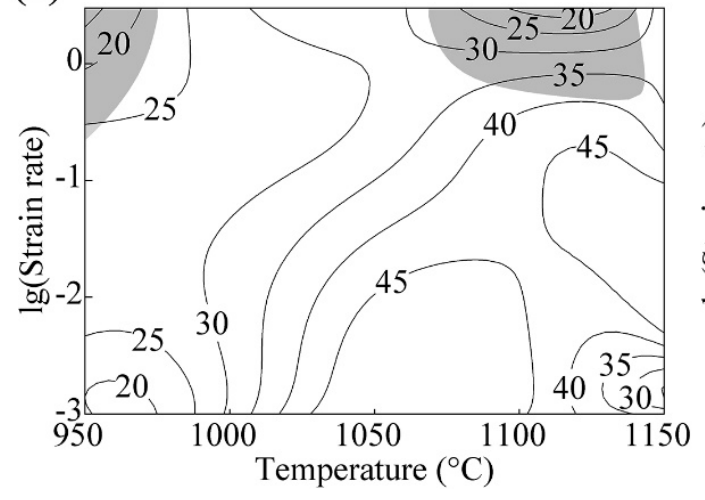

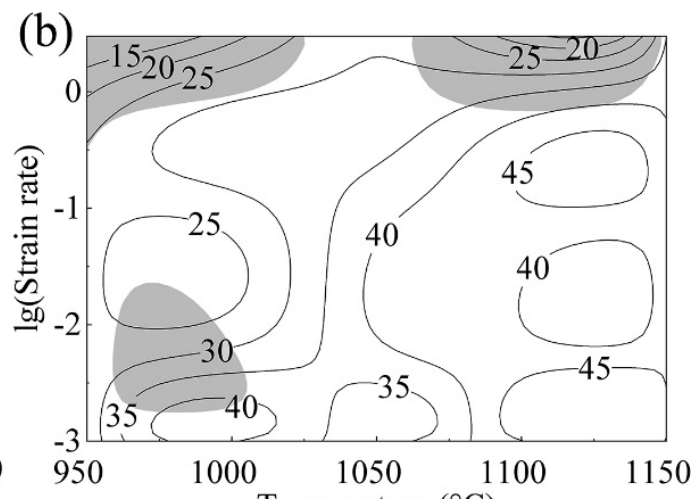

(d)

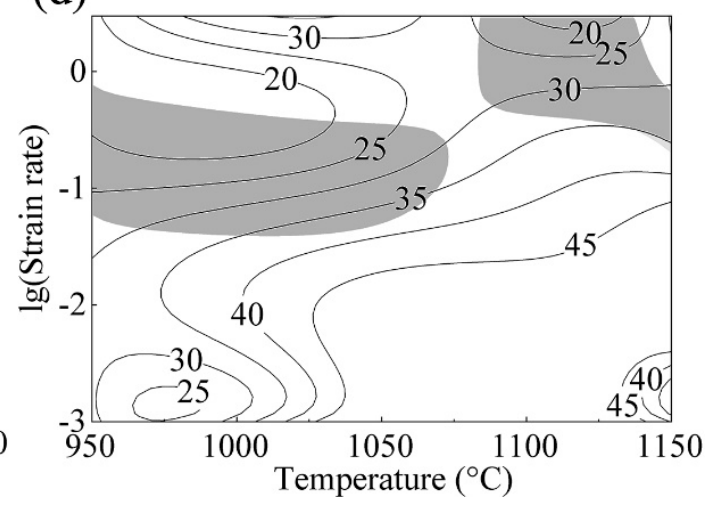

Figure 7. Processing maps of GH4698 at the strains of (a) 0.2 , (b) $0.4,(\mathbf{c}) 0.6$, and (d) 0.8 .
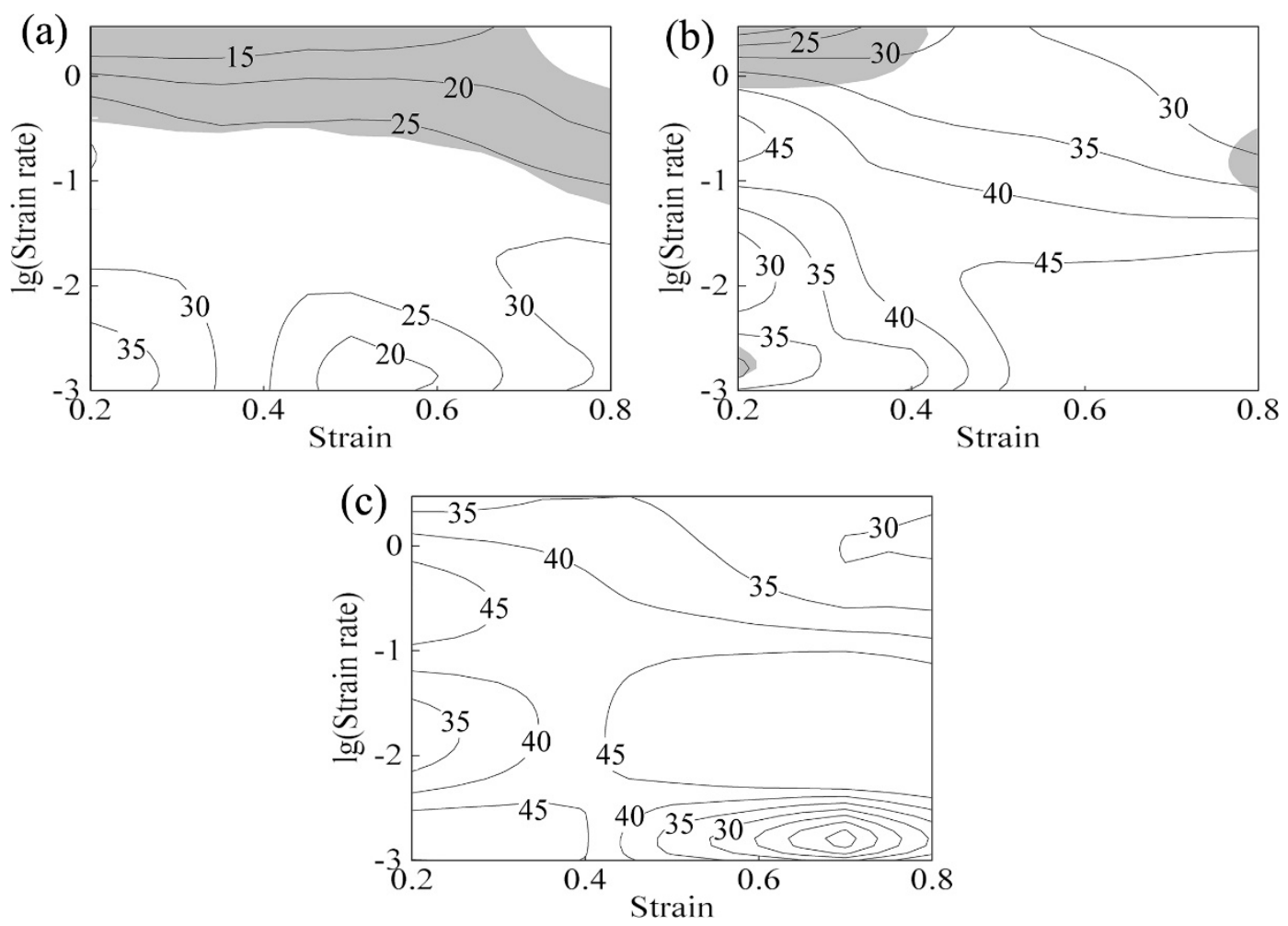

Figure 8. Processing maps of GH4698 at the temperatures of (a) $950{ }^{\circ} \mathrm{C},(\mathbf{b}) 1050{ }^{\circ} \mathrm{C}$, and (c) $1150{ }^{\circ} \mathrm{C}$.

Hot working maps of a GH4698 alloy at various strain rates are shown in Figure 9. Good hot working abilities were obtained at $0.001 \mathrm{~s}^{-1}$, as no deformation instability domain was found, as shown 
in Figure 9a. A dissipation coefficient of $\sim 45 \%$ at $1050-1150{ }^{\circ} \mathrm{C}$ and at the strain of $0.4-0.8$ showed that a full dynamic recrystallization followed by dramatic grain growth might have occurred. A deformation instability domain at $950-1050{ }^{\circ} \mathrm{C}$ and at the strain of $0.75-0.8$ could be observed at $0.1 \mathrm{~s}^{-1}$, as shown in Figure $9 \mathrm{~b}$, and a relatively high dissipation coefficient of $\sim 40 \%$ could still be obtained, meaning that the thermal processing parameters were still acceptable. However, the deformation instability domain occupied the majority of the processing map, as shown in Figure 9c, indicating that the GH4698 alloy should not be hot-formed at such a fast strain rate, as deformation instability and local material flow would occur.

Based on the results presented in Figures 7-9, the optimal hot working parameters were suggested as $1080-1150{ }^{\circ} \mathrm{C}$ and $0.004-0.1 \mathrm{~s}^{-1}$. The forging temperature should be no lower than $1050{ }^{\circ} \mathrm{C}$ to ensure that dynamic recrystallization occurs completely, and the strain rate should be neither too high to avoid deformation instability, nor too low to prevent grain coarsening. The visible differences in the shape of the stress-strain curves in this research and in the literature [22] might lead to the difference of the shape of the processing maps. Therefore, further research should be carried out to quantify the influence of chemical compositions. In the practical production of GH4698 large forgings, the forging temperature can be determined by the pressure that the forging device can provide. The results also showed that the GH4698 alloy was suitable for low-speed isothermal forgings at high temperatures $\left(1080-1150{ }^{\circ} \mathrm{C}\right)$.
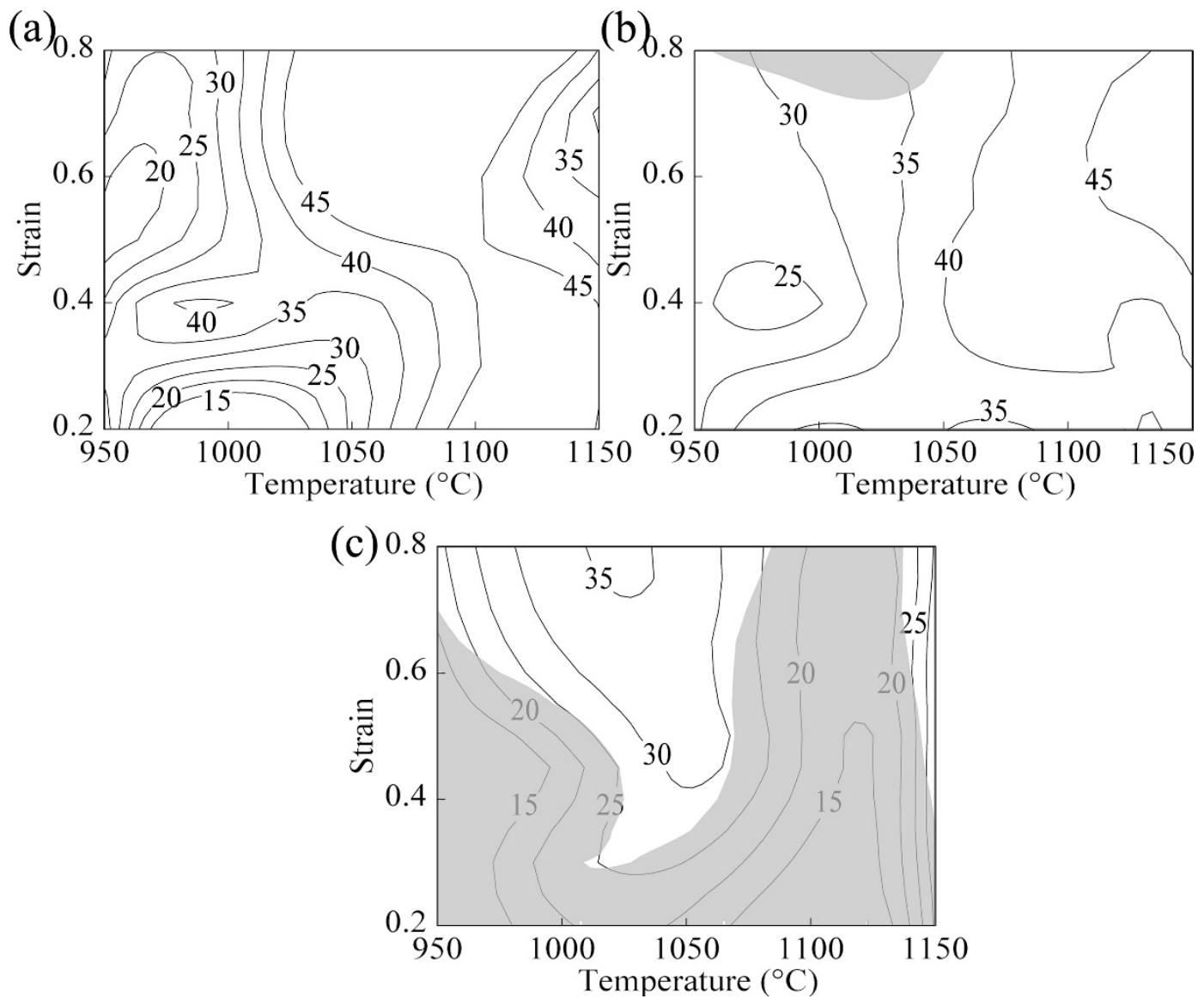

Figure 9. Processing maps of GH4698 at the strain rates of (a) $0.001 \mathrm{~s}^{-1}$, (b) $0.1 \mathrm{~s}^{-1}$, and (c) $3 \mathrm{~s}^{-1}$.

\section{Conclusions}

Hot compression tests were performed at 950-1150 ${ }^{\circ} \mathrm{C}$ and $0.001-3 \mathrm{~s}^{-1}$, and the following conclusions could be drawn: 
(1) The stress-strain curves of GH4698 were single-peaked at various compression conditions, owing to dislocation motions during dynamic recrystallizations. The peak flow stress agreed well with the results in the literature, but the stress-strain curve shapes were different, which may be attributed to differences in the as-received material states.

(2) An Arrhenius model was established to calculate the stress evolutions under various strain rates, temperatures, and strains. The average calculation error was $10.96 \mathrm{MPa}(5.90 \%)$, showing that the model could accurately describe the flow behaviors of GH4698 at high temperatures.

(3) The processing maps of GH4698 revealed that the hot working ability of GH4698 markedly decreased under lower temperatures $\left(950-1080^{\circ} \mathrm{C}\right)$ and high strain rates $\left(0.1-3 \mathrm{~s}^{-1}\right)$. The optimal hot working parameters were suggested as $1080-1150^{\circ} \mathrm{C}$ and $0.004-0.1 \mathrm{~s}^{-1}$. Moreover, according to this study, the GH4698 alloy was suitable for low-speed isothermal forgings at high temperatures $\left(1080-1150{ }^{\circ} \mathrm{C}\right)$.

Author Contributions: Writing—original draft preparation, R.C.; writing—review and editing, H.X.; funding acquisition, M.W. and J.L.

Funding: This study was funded by the National Natural Science Foundation of China (51435007), the Natural Science Foundation of Hubei province (2017CFB587), the State Key Laboratory of Materials Processing and Die \& Mould Technology in Huazhong University of Science and Technology (P2020-015), the Outstanding Young Scientific \&Technological Innovation Team Plan of Colleges and Universities in Hubei Province (T201518), the Hubei Key Laboratory of Automotive Power Train and Electronic Control in Hubei University of Automotive Technology (ZDK1201601), and the Doctoral Scientific Research Fund of Hubei University of Automotive Technology (BK201901).

Conflicts of Interest: The authors declare that they have no conflicts of interest.

\section{References}

1. Huang, B.; Li, C.; Shi, L. Nonferrous Metal materials and engineering. In China Materials Engineering Canon; Chemical Industry Press: Beijing, China, 2005; Volume 4, pp. 378-391.

2. Wang, J.; Guo, W.; Li, P. Modified Johnson-Cook description of wide temperature and strain rate measurements made on a nickel-base superalloy. Mater. High Temp. 2017, 34, 157-165. [CrossRef]

3. Shamsolhodaei, A.; Zarei-Hanzaki, A.; Ghambari, M. The high temperature flow behavior modeling of NiTi shape memory alloy employing phenomenological and physical based constitutive models: A comparative study. Intermetallics 2014, 53, 140-149. [CrossRef]

4. Chen, R.; Zheng, Z.; Li, J. Constitutive Modelling and Hot Workability Analysis by Microstructure Examination of GH4169 Alloy. Crystals 2018, 8, 282. [CrossRef]

5. Wang, L.; Liu, F.; Cheng, J. Arrhenius-Type Constitutive Model for High Temperature Flow Stress in a Nickel-Based Corrosion-Resistant Alloy. J. Mater. Eng. Perform. 2016, 25, 1394-1406. [CrossRef]

6. Gu, S.; Zhang, L.; Zhang, C. Constitutive Modeling for Flow Stress Behavior of Nimonic 80A Superalloy During Hot Deformation Process. High Temp. Mater. Process. 2016, 35, 327-336. [CrossRef]

7. Linl, Y.C.; Nong, F.Q.; Chen, X.M. Microstructural evolution and constitutive models to predict hot deformation behaviors of a nickel-based superalloy. Vacuum 2017, 137, 104-114. [CrossRef]

8. Wang, T.; Wan, Z.; Sun, Y. Dynamic Softening Behavior and Microstructure Evolution of Nickel Base Superalloy. Acta Metall. Sin. 2018, 54, 83-92. [CrossRef]

9. Lin, Y.C.; Wen, D.X.; Li, X.H. Hot deformation characteristics and dislocation substructure evolution of a nickel-base alloy considering effects of $\delta$ phase. J. Alloys Compd. 2018, 764, 1008-1020. [CrossRef]

10. Haan, J.; Bezold, A.; Broeckmann, C. Interaction between particle precipitation and creep behavior in the NI-base Alloy 617B: Microstructural observations and constitutive material model. Mater. Sci. Eng. A 2015, 640, 305-313. [CrossRef]

11. Zhou, H.; Zhang, H.; Liu, J. Prediction of Flow Stresses for a Typical Nickel-Based Superalloy During Hot Deformation Based on Dynamic Recrystallization Kinetic Equation. Rare Met. Mater. Eng. 2018, 47, 3329-3337. [CrossRef]

12. Wu, Y.; Zhang, M.; Xie, X. Hot deformation characteristics and processing map analysis of a new designed nickel-based alloy for $700{ }^{\circ} \mathrm{C}$ A-USC power plant. J. Alloys Compd. 2016, 656, 119-131. [CrossRef] 
13. Wang, L.; Liu, F.; Zuo, Q. Processing Map and Mechanism of Hot Deformation of a Corrosion-Resistant Nickel-Based Alloy. J. Mater. Eng. Perform. 2017, 26, 392-406. [CrossRef]

14. Wang, L.; Liu, F.; Cheng, J. Hot deformation characteristics and processing map analysis for Nickel-based corrosion resistant alloy. J. Alloys Compd. 2015, 623, 69-78. [CrossRef]

15. Jiang, H.; Dong, J.; Zhang, M. Hot deformation characteristics of Alloy 617B nickel-based superalloy: A study using processing map. J. Alloys Compd. 2015, 647, 338-350. [CrossRef]

16. Kang, F.; Zhang, X.; Sun, J. Hot Deformation Behavior and Processing Map of a Nickel-Base Superalloy GH4169. Adv. Mater. Res. 2013, 834, 432-436. [CrossRef]

17. Gegel, H.L. Synthesis of Atomistics and Continuum Modeling to Describe Microstructure: Computer Simulation in Material Science; ASM Park: Geauga, OH, USA, 1984; pp. 291-344.

18. Malas, J.C.; Seetharaman, V. Using material behavior models to develop process control strategies. JOM 1992, 44, 8-13. [CrossRef]

19. Prasad, Y.V.R.K.; Seshachryuly, T. Modelling of hot deformation for microstructural control. Int. Mater. Rev. 1988, 43, 243-252. [CrossRef]

20. Murty, S.V.S.N.; Rao, B.N. On the development of instability criteria during hot working with reference to IN 718. Mater. Sci. Eng. A 1998, 254, 76-82. [CrossRef]

21. Zhou, G.; Ding, H.; Cao, F.R.; Han, Y.B.; Zhang, B.J. Flow instability criteria in processing map of superalloy GH79. Trans. Nonferrous Met. Soc. Chin. 2012, 22, 1575-1581. [CrossRef]

22. Zhang, P.; Hu, C.; Zhu, Q. Hot compression deformation and constitutive modeling of GH4698 alloy. Mater. Des. 2015, 65, 1153-1160. [CrossRef]

23. Chen, R.; Zheng, Z.; Li, N. In-situ investigation of phase transformation behaviors of $300 \mathrm{M}$ steel in continuous cooling process. Mater. Charact. 2018, 144, 400-410. [CrossRef]

24. Chen, R.; Zheng, Z.; Li, J. In Situ Investigation of Grain Evolution of 300M Steel in Isothermal Holding Process. Materials 2018, 11, 1862. [CrossRef] [PubMed]

25. Chen, R.; Guo, P.; Zheng, Z. Dislocation Based Flow Stress Model of 300M Steel in Isothermal Compression Process. Materials 2018, 11, 972. [CrossRef] [PubMed]

26. Prasad, Y.V.R.K.; Gegel, H.L.; Doraivelu, S.M. Modeling of dynamic material behavior in hot deformation: Forging of Ti6242. Metall. Trans. A 1984, 15, 1883-1892. [CrossRef]

27. Yin, F.; Hua, L.; Mao, H. Constitutive modeling for flow behavior of GCr15 steel under hot compression experiments. Mater. Des. 2013, 43, 393-401. [CrossRef]

28. Zhang, X.; Huang, L.; Li, J. Flow behaviors and constitutive model of 300M high strength steel at elevated temperature. J. Cent. South Univ. 2017, 48, 1439-1447. [CrossRef] 